landmark, Vogel and Motulsky's Human genetics, which set the seal on Human Genetics as a major scientific speciality. With these two authoritative textbooks to guide him the Medical Geneticist can now feel confident that his field has its own identity, with solid clinical and theoretical foundations.

This book is a multi-author work and could indeed have been written in no other way, bearing in mind the extent of detailed information presented. Inevitably this means some loss of unity, and one tends to read and judge it as individual chapters rather than as a whole. In this respect it is no different from most other textbooks, however good their quality, but it does mean that its value is greater for the specific topics than for the general and theoretical sections.

The organisation of the book (in two volumes) follows the classical textbook pattern of a series of general chapters, followed by sections on each major body system, chromosomal and metabolic disorders rightly being classed as systems in this framework. In all sections the overall impression is one of high quality and here the editors' role shows its value, since the quality of each chapter naturally reflects its author. The very large number of authors means that each is for the most part covering his own area of expertise rather than ranging too far into neighbouring fields. Overlap is not a major problem and the sequence of chapters and sections is smooth, in contrast to many multi-author works.

In such a major work it would be easy but pointless to pick out inferior chapters; they do exist but are very few. The great majority, particularly those dealing with specific disorders, are accurate and comprehensive. Of the major Mendelian disorders, only Huntington's disease and cystic fibrosis struck the reviewer as needing more extensive coverage. The sections on skeletal disorders and on endocrine and metabolic disease are particularly satisfying and most authors effectively use tables to include the details that need recording but cannot be discussed in full. Dating of material is a problem with all textbooks and this is no exception. The rapidity of advances in the past four years means that little of the revolution resulting from application of recombinant DNA techniques appears here. In general, however, there is little in the book that has been made incorrect by these advances.

High quality of illustrations, especially clinical photographs, is a particularly pleasing feature-a contrast to many text books. The quality of print and general layout is also high. The weight of the volumes has not prevented them vanishing frequently from my shelves!

Is there really a need for major textbooks of this type? In my opinion the answer is "yes, if they are really good", and this book certainly falls into this category.

In Medical Genetics there is a particular need for synthesis of scattered information, and there can be no doubt that this book will be really used.

Having produced such a major work, the editors and publisher have a serious responsibility to ensure that it is kept updated and, where possible, improved. The publisher should recognise this by giving a firm commitment to a future edition, with a definite date fixed well ahead to allow contributors time for revision. The editors should do some selective, but nonetheless firm, pruning as well as some talent spotting, to ensure that the book stays in the forefront of the field. There is not likely to be a serious alternative to this book; its success and its quality will reflect that of the speciality during the coming years.

Peter S Harper

\section{The Antibody Enigma}

By T J Kindt and J D Capra. (Pp xvi + 270; figures + tables.) New York, London: Plenum Press. 1984.

The enigma in the title of this book refers to the problems of accounting for the diversity of antibodies which can be synthesised in the body. The authors approach the problem with an essentially historical perspective and carefully trace and describe the gradual evolution of the various theories designed to explain the phenomenon. Early data from serologists, biochemists, and geneticists all revealed the complexity of the immunoglobulin populations and the capability of producing vast numbers of different antibodies. Two major theories gradually emerged: the germ-line theory, which proposed that each antibody is the product of a specific gene; and the somatic mutation theory, which proposed that immunoglobulin diversity resulted from somatic events affecting a limited number of genes. Much supportive evidence was assembled by the proponents of these two contrasting theories. However, since neither was completely satisfactory, a number of what the authors call "Maverick solutions" were proposed, such as Kabat and Wu's episomal insertion hypothesis, Capra and Kindt's gene interaction hypothesis, Smithies' DNA network hypothesis, and Edelman and Gally's somatic recombination hypothesis. The true picture was only to emerge with the advent of recombinant DNA technology which, interestingly, then showed that there has been some element of truth in each of these earlier theories. What is now clear is that there are a large number of germ line $\mathrm{V}, \mathrm{D}$, and $\mathrm{J}$ genes which recombine in various combinations, but this diversi- 
ty is further added to by 'recombinational flexibility' at the points where the gene segments join together, and even further diversity is contributed by somatic mutations.

A little disappointingly the Dreyer-Bennett hypothesis, which many consider was seminal to ideas concerning the origin of antibody diversity, is mentioned only briefly in the text and does not appear at all in the index. Perhaps the book is also a little repetitious, though to those readers like myself who may be unfamiliar with many of the details, this can be helpful. The story is told in a well referenced and detailed yet interesting manner, and should appeal to many of those with interests in this exciting field of molecular biology.

\section{Alan E H Emery}

Birth Defects: Clinical and Ethical Considerations Annual Review of Birth Defects, 1982. Sponsored by the March of Dimes Birth Defects Foundation held in Birmingham, Alabama, June 1982. Edited by S C Finley, W H Finley, and C E Flowers Jr. Birth Defects: Original Article Series, Vol 19, No 5. (Pp xii +240 ; figures + tables. \$37.00.) New York: March of Dimes Birth Defects Foundation and Alan R Liss. 1983.

This book is a report of the 1982 March of Dimes Birth Defects meeting which was held in Birmingham, Alabama. In the opening remarks the President (for Medical Services, March of Dimes. Birth Defects Foundation) widens the definition of Birth
Defects to include premature infants since "(they) $\stackrel{\overparen{D}}{\rightarrow}$ are abnormal in structure because of their small- $\overrightarrow{\bar{B}}$ ness. ...". This widened definition is necessary in relation to this book since although the title suggests that there is a definite theme and the contents are linked with each other, this is far from the case. The contents range from general to specific dysmorphol- $\varrho$ ogy, from obstetric management of preterm labour is to the effects of the New Federalism on delivery of $\vec{\circ}$ genetic services, and from clinical application of restriction endonuclease analysis to discussion of $\vec{\omega}$ granting of "greater moral status to the fetus". This heterogeneity of content means that it is difficult to know to whom the book should be recommended. In 234 pages there are 14 papers and 65 abstracts, so few of the subjects are reported in depth or detail. i

Several of the papers deal with delivery of genetic $\mathscr{\omega}$ and perinatal services and, while there are some 을 lessons to be learnt, the details are not relevant to those of us outside the United States. I did find two $ᄃ$ papers valuable, one on high resolution cytogenetics by Yunis and Lewandowski, who gave a useful review of the subject for the clinician, and one which was scholarly and practical by John Fletcher, considering ethical aspects of prenatal diagnosis and fetal therapy.

The Birth Defects Conferences may benefit from the widened scope of subjects covered and professional groups represented but the published reports suffer from this change. There are valuable facts and discussions contained within the volume but it cannot be recommended for personal purchase though specialised libraries should obtain a copy.

Dian DonnaI 